\title{
Microstructure and mechanical properties of A357/SiC nanocomposites fabricated by ultrasonic cavitation-based dispersion of ball-milled nanoparticles
}

Journal of Composite Materials 2017, Vol. 5I(3) 395-404 (C) The Author(s) 2016 Reprints and permissions: sagepub.co.uk/journalsPermissions.nav DOI: I0.II77/00219983 I6644850 journals.sagepub.com/home/jcm

SAGE

\author{
Sinan Kandemir
}

\begin{abstract}
In this work, A357/0.5 wt.\% SiC nanocomposites were fabricated with a combination of ultrasonic processing and a nanoparticle feeding mechanism that involves the introduction of a closed end aluminium tube filled with the ball-milled $\mathrm{SiC}$ nanoparticles $(20-30 \mathrm{~nm})$ and aluminium powders $(<75 \mu \mathrm{m})$ into the melt for complete deagglomeration and uniform dispersion of nanoparticles through the matrix. The microstructural and mechanical properties of the fabricated nanocomposites were investigated. The microstructural studies conducted with optical and advanced electron microscopes indicate that relatively effective deagglomeration and uniform dispersion of SiC nanoparticles into the molten alloy were achieved. The hardness and tensile properties of the nanocomposites were notably improved compared to those of the ultrasonically processed A357 alloy without reinforcement, showing the strengthening potency of nanoparticles and the good bonding obtained at the particle-reinforcement interface.
\end{abstract}

\section{Keywords}

Metal matrix nanocomposite, SiC nanoparticles, ultrasonic processing, mechanical properties

\section{Introduction}

Metal matrix nanocomposites (MMNCs), in which metals are strengthened with nano-sized ceramic or other hard constituents, have attracted a great deal of attention in the last two decades for their potential to significantly enhance mechanical properties of light alloys compared to the properties of conventional metal matrix composites (where the reinforcing constituents are micron-sized). ${ }^{1-6}$ Unlike micron-sized particles, it was shown that a relatively low addition of nanoparticles, e.g. $0.1-2.0 \mathrm{wt} . \%$, could manage to effectively strengthen the matrices obstructing dislocation and grain boundary motion while maintaining or even improving the ductility. ${ }^{7-10}$ Therefore, MMNCs can offer new opportunities for the automotive and aerospace industries to produce lightweight and highstrength metallic components which could contribute to weight reduction and thus energy efficiency. However, the wide use of MMNCs is restricted due to the cost of composite manufacturing along with the challenges in achieving uniform distribution of nanoparticles through the matrix and good matrix-reinforcement interfacial bonding, which govern composite mechanical properties. ${ }^{7}$

Among the available fabrication routes for MMNCs including powder metallurgy and preform impregnation, the liquid state routes that combine the dispersion of reinforcement into molten metals with subsequent casting have emerged as the most economical and versatile routes for the production of engineering parts with complex shapes. ${ }^{7,11}$ It is well known that the major issue associated with the incorporation of ceramic-based nanoparticles into liquid metals is these nanoparticles' large surface-to-volume ratio and poor wettability that can easily lead to agglomeration and clustering. However, a number of studies ${ }^{1-14}$ showed that good dispersion of ceramic nanoparticles in molten

Department of Mechanical Engineering, Izmir Institute of Technology, Urla, Izmir, Turkey

\section{Corresponding author:}

Sinan Kandemir, Department of Mechanical Engineering, Izmir Institute of Technology, Gulbahce, 35430 Urla, Izmir, Turkey.

Email: sinankandemir@iyte.edu.tr 
aluminium and magnesium alloys could be obtained by ultrasonic processing due to the application of high-intensity ultrasonic waves in the matrix with localised implosive impact, i.e. transient cavitation and acoustic streaming. It is hypothesised that this coupled impact could break nanoparticle agglomerates and distribute the nanoparticles broken from the agglomerates throughout the matrix. ${ }^{15,16}$ In addition, it has been suggested that ultrasonic cavitation could promote the wettability of ceramic particles by molten metals as it may remove the absorbed gases on the particle surface. ${ }^{17}$

Apart from the wetting and large surface area issues of nanoparticles, the particle feeding mechanism is also considered to play a crucial role during ultrasonic processing in the fabrication of MMNCs for effective particle dispersion. ${ }^{18}$ In this direction, several nanoparticle feeding mechanisms, as summarised elsewhere, ${ }^{19}$ have been investigated. However, the majority of these mechanisms could not manage complete particle entry into the melt, which is usually difficult for aluminium matrices due to ready formation of oxide layer on the melt surface even with the use of an argon protective atmosphere. Choi et al. ${ }^{20}$ designed and built an automated single screw nanoparticle feeding system equipped with a steel made feeding tube that is submerged into the melt in order to effectively incorporate nanoparticles into liquid magnesium alloys controlling particle feeding rate. However, this system is limited for the processing of aluminium alloys, since a chemical reaction is more likely to occur between the steel tube and molten aluminium contaminating the melt. In recent studies, ${ }^{21,22}$ the mixing of nanoparticles with aluminium powders followed by compaction has been employed to form master alloys which are then fed into molten aluminium alloys under ultrasonic cavitation. In addition, Jiang and Wang ${ }^{23,24}$ have combined ultrasonic treatment with semi-solid mechanical stirring to prevent the segregation of nanoparticles into aluminium alloys, which could be encountered just after the application of ultrasound in fully liquid matrices. Although the introduction of compacted master alloys into the melt and ultrasonic assisted semi-solid stirring showed substantial improvements in terms of facilitating nanoparticle entry and dispersion into the melt, they have not been found to aid complete deagglomeration of nanoparticles.

In the present study, ball milling that is known to be a suitable technique for fine and uniform dispersion of nano or micron-sized particulates has been utilised to mix the ceramic nanoparticles with pure aluminium powders. It has been proposed that the application of ball milling could assure the deagglomeration of nanoparticles prior to any treatment of molten composite and hence maximising mechanical properties.
Table I. Chemical composition of A357 alloy used in the present study (wt.\%).

\begin{tabular}{llllllll}
\hline $\mathrm{Al}$ & $\mathrm{Si}$ & $\mathrm{Fe}$ & $\mathrm{Cu}$ & $\mathrm{Mn}$ & $\mathrm{Mg}$ & $\mathrm{Zn}$ & $\mathrm{Ti}$ \\
\hline Bal. & 7.0 & 0.2 & 0.02 & 0.03 & 0.3 & 0.04 & 0.08 \\
\hline
\end{tabular}

Therefore, aluminium alloys have been reinforced by combining ultrasonic processing with a particular feeding mechanism that involves the introduction of a closed end aluminium tube filled with the ball-milled nanoparticles and aluminium powders into the melt, as described here. Finally, the microstructural and mechanical properties of the fabricated nanocomposites have been investigated. This particle feeding mechanism allowing enhanced dispersion of nanoparticles in aluminium demonstrates that engine components, e.g. pistons and connecting rods, with high specific strength are likely to be manufactured from MMNCs.

\section{Experimental procedures}

\section{Materials}

In this work, $\beta$-SiC nanoparticles (Nanostructured \& Amorphous Materials Inc., $20-30 \mathrm{~nm}$ average particle diameter and $>97 \%$ purity) were used as the reinforcement to fabricate aluminium matrix nanocomposites due to their nearly identical density to that of aluminium alloys. A357 commercial aluminium casting alloy (composition shown in Table 1) was selected as the matrix since the presence of $7.0 \mathrm{wt} . \%$ silicon in its composition could potentially suppress the formation of $\mathrm{Al}_{4} \mathrm{C}_{3}$ that is an undesired compound originated from the chemical reaction between liquid aluminium and $\mathrm{SiC}$, below $700^{\circ} \mathrm{C} .^{25}$ Aluminium powders supplied by Sigma-Aldrich with an average particle size of $<75 \mu \mathrm{m}$ and purity of $99 \%$ were used for the deagglomeration of nanoparticles with ball milling prior to the nanoparticles feeding into the melt.

\section{Experimental setup}

The schematic experimental setup for the ultrasonic dispersion of SiC nanoparticles into A357 alloy is demonstrated in Figure 1. This experimental setup comprises an electrical resistance furnace, a commercially available ultrasonic unit (Q700 sonicator manufactured by Qsonica, LLC) and a nanoparticle feeding unit. The air cooled ultrasonic system which is capable of generating a $20 \mathrm{kHz}$ ultrasound wave with a maximum $700 \mathrm{~W}$ power output to effectively disperse the nanoparticles into the matrix consists of four major components: generator, transducer, booster and probe. The probe transmitting ultrasound waves into the liquid are made of 


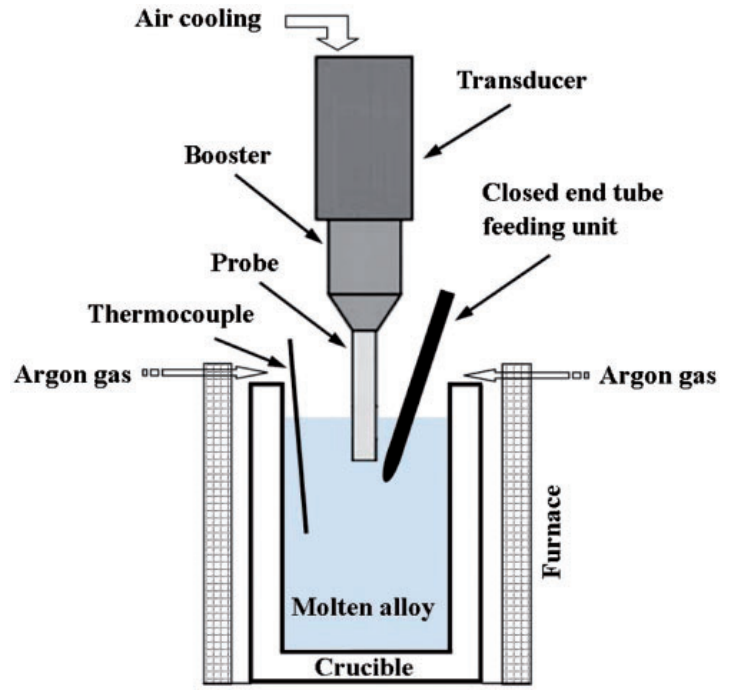

Figure I. Schematic of experimental arrangement for ultrasonic processing of MMNCs.

Ti-6Al-4 V titanium alloy that is known to be a most suitable material for relatively high temperature applications up to $660^{\circ} \mathrm{C}$. However, the majority of commercial ultrasonic probes are designed for operations at room temperature. Therefore, the titanium probe with a diameter of $12.7 \mathrm{~mm}$ was modified extending its length based on the procedure described by Kandemir et al. $^{21}$ to process liquid aluminium.

A closed end tube feeding method was employed to feed $\mathrm{SiC}$ nanoparticles into the melt. In this method, $9 \mathrm{~g}$ aluminium powders and $1 \mathrm{~g} \mathrm{SiC}$ nanoparticles corresponding $10 \mathrm{wt} . \% \mathrm{SiC}$ were first mixed in a planetary ball mill (Retsch PM 200) for $2 \mathrm{~h}$ at $350 \mathrm{r} / \mathrm{min}$. The process was interrupted for $3 \mathrm{~min}$ after each $10 \mathrm{~min}$ of milling time in order to avoid excessive temperature rise. The alumina balls-to-powder weight ratio was 2.5:1 and the diameter of the balls was approximately $9.5 \mathrm{~mm} ; 5 \mathrm{~g}$ of the ball-milled particles was then filled into a closed end tube which is made of A357 alloy (same as the matrix alloy) with an outside diameter of $6 \mathrm{~mm}$, a wall thickness of $0.5 \mathrm{~mm}$ and $150 \mathrm{~mm}$ length. Finally, the mixture in the tube was gently pressed by hand using a plunger to form the tube feeding unit. It is envisioned that the gradual melting of tube and aluminium powders in the feeding unit would enhance the incorporation of $\mathrm{SiC}$ nanoparticles into the melt.

\section{Fabrication of nanocomposites}

Approximately, $180 \mathrm{~g}$ of A357 alloy chunks was melted in a graphite crucible (salamander 0.5 type) and held at $700^{\circ} \mathrm{C}$ for $15 \mathrm{~min}$ for homogenisation under protective argon gas. The ultrasonic probe was submerged into the molten alloy about $12-13 \mathrm{~mm}$ from the melt surface. Once the temperature decreased to $660^{\circ} \mathrm{C}$ to ensure that titanium probe would not react with liquid aluminium, the ultrasonic vibration was applied with a peak-to-peak amplitude of about $45 \mu \mathrm{m}$. During the sonication, a prepared closed end aluminium tube feeding unit containing the ball-milled $\mathrm{SiC}$ nanoparticles and aluminium powders was introduced into the melt just under the probe where the maximum ultrasonic intensity occurs, i.e. the cavitation zone. ${ }^{26}$ After feeding each tube (about $3 \mathrm{~min}$ ), the melt was ultrasonically processed for further $15 \mathrm{~min}$ at $655-660^{\circ} \mathrm{C}$, completing a total ultrasonic processing time of $30 \mathrm{~min}$ for two feeding tubes. Then, the probe was removed from the melt and the temperature of the melt was increased to $700^{\circ} \mathrm{C}$ for pouring. The composite melt was cast into a steel mould preheated to $300^{\circ} \mathrm{C}$ to produce tensile test specimens. The content of $\mathrm{SiC}$ nanoparticles in the composite was calculated as 0.5 wt. $\%$. In addition, the unreinforced A357 reference alloys were produced with the similar ultrasonic processing parameters. Hence, any difference in the properties of reinforced and unreinforced alloys is most likely to be due to the effect of nanoparticles.

\section{Microstructural and mechanical characterisations}

For microstructural characterisation, the samples which were ground and polished to a $0.25 \mu \mathrm{m}$ finish with a diamond-based suspension were examined by means of an optical microscope (Leica DM2500 M) and a scanning electron microscope (SEM, FEI Quanta FEG 250) fitted with an energy dispersive X-ray spectroscopy (EDX) system. Transmission electron microscopy (TEM) and selected area electron diffraction (SAED) measurements were performed with a JEOL 2100 microscope operating at $200 \mathrm{kV}$ for detailed analysis in order to ascertain whether the nanoparticles were incorporated into the matrix and any chemical reaction took place between the matrix and particle surface. The nanocomposite TEM samples, which were in the form of $3 \mathrm{~mm}$ diameter discs, were polished to $50-60 \mu \mathrm{m}$ thickness and dimpled at the centre. The dimpled discs were then ion-milled using a Gatan precision ion beam polishing system under an argon atmosphere with the parameters of a $4^{\circ}$ angle, $5 \mathrm{kV}$ gun voltage and $3 \mathrm{r} / \mathrm{min}$ disc rotation.

The Vickers hardness was performed for the macrohardness testing of samples with a Zwick/Roell ZHU 2.5 tester by applying a load of $5 \mathrm{kgf}$ for $10 \mathrm{~s}$. Each hardness value is the average of at least 20 measurements from different locations of each sample. For tensile testing, the dog bone style specimens with a gage length of $20 \mathrm{~mm}$ and a gage section diameter of $6 \mathrm{~mm}$ were cut from unreinforced and $\mathrm{SiC}$ nanoparticle reinforced $\mathrm{A} 357$ alloy casts based on ASTM E 8/E 8M-08 standards. 


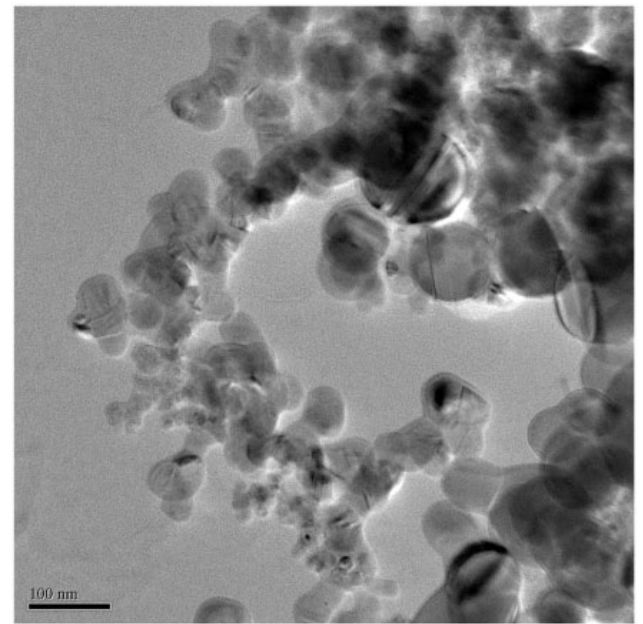

Figure 2. A TEM image of the SiC used in this study.

The tensile properties of reference material and nanocomposites were determined using a 793 model MTS tensile testing machine with $2 \mathrm{~mm} / \mathrm{min}$ crosshead speed at room temperature. Six tensile specimens were tested for each sample and the average value was reported.

\section{Results and discussion}

\section{Ball milling of SiC nanoparticles and Al powders}

A TEM image of the SiC nanoparticles and a secondary electron (SE) image of the $\mathrm{Al}$ powders used in the fabrication of nanocomposites are given in Figures 2 and 3, respectively. It is clear from Figure 2 that the nanoparticles tend to appear as agglomerates and clusters in the assupplied state. Figure 4 indicates the microstructure of $2 \mathrm{~h}$ ball-milled $\mathrm{Al}$ powders and $\mathrm{SiC}$ nanoparticles along with the EDX analysis, in which Si map potentially represents the $\mathrm{SiC}$ nanoparticles (C map was not included in the analysis as the data were also collected from the carbon tape where the particles sit in the SEM chamber). Unlike the as-received separated $\mathrm{Al}$ powders, it is seen that the Al powders were clustered more likely due to the heat generated during ball milling. A close-up image of the ball-milled particles in Figure 5 shows that the ball milling of $\mathrm{SiC}$ nanoparticles with $\mathrm{Al}$ powders has apparently led to the deagglomeration of relatively large-sized nanoparticle clusters and a reasonable dispersion of the $\mathrm{SiC}$ nanoparticles on the $\mathrm{Al}$ powder surface.

\section{Microstructural characterisation of the fabricated nanocomposites}

The optical micrographs of the ultrasonically processed A357 alloy without the addition of reinforcements (reference alloy) and the fabricated A357/0.5 wt.\% SiC nanocomposite are compared in Figure 6. As seen

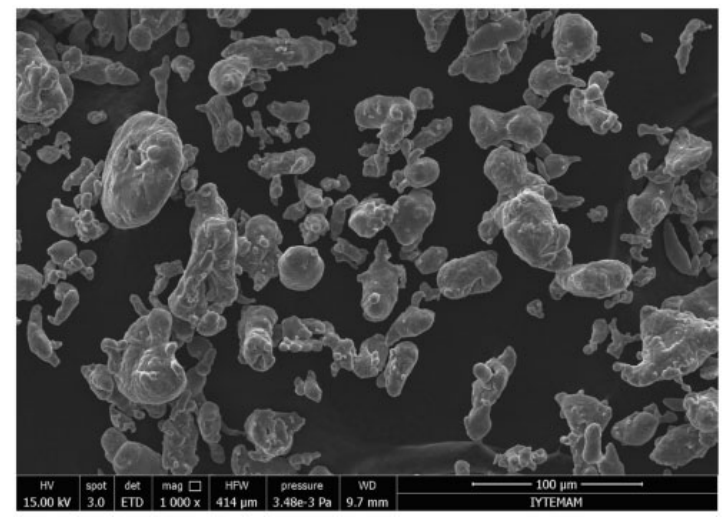

Figure 3. SE image of the as-supplied aluminium powders with $<75 \mu \mathrm{m}$ average particle diameter.

from the figure, the introduction of $\mathrm{SiC}$ nanoparticles into the matrix has led to significant refinement in the microstructure altering the morphology of $\alpha$-aluminium grains from larger dendrites to relatively small dendrites and finer structure with eutectic distributed between globules in comparison with the reference alloy. This refinement could be attributed to the nucleation catalysis effect of nanoparticles on the primary Al phase promoting fine grain sizes. ${ }^{8,27}$ Also, no distinction was observed between the reference alloy and the nanocomposite in terms of porosity level.

During the particle feeding and ultrasonic processing of the nanocomposites, no obvious rejection of ballmilled nanoparticle clusters to the melt surface and to the crucible wall was observed. The SEM images of the nanocomposite shown in Figure 7 may suggest that the feeding loose particles rather than compacted particles into the melt prevented the presence of undispersed remnant pieces of the feeding unit in the microstructure as no such a structure was observed (this problem is commonly encountered in the feeding of compacts under ultrasonic cavitation as they tend to be broken into small pieces and to sink or attach the crucible wall, where the ultrasonic intensity is relatively low to completely distribute nanoparticles into the melt ${ }^{21}$ ). In addition, Figure 7(c) and (d) reveals that the $\mathrm{SiC}$ nanoparticles were incorporated into both $\alpha$-aluminium grains and Al-Si eutectic regions (grain boundaries) in spite of the fact that it is hard to locate nano-sized elements due to the spatial resolution limit of the SEM. It could be implied that relatively larger ballmilled $\mathrm{SiC}$ nanoparticle clusters were further deagglomerated into the clusters with less than $0.5 \mu \mathrm{m}$ in size as well as possible evenly distributed nanoparticles upon ultrasonic processing (Figure 7(d)).

The microstructures of several locations in the nanocomposite cast block were investigated to determine the degree of nanoparticle distribution into the matrix as illustrated in Figure 8. Almost every region analysed in 


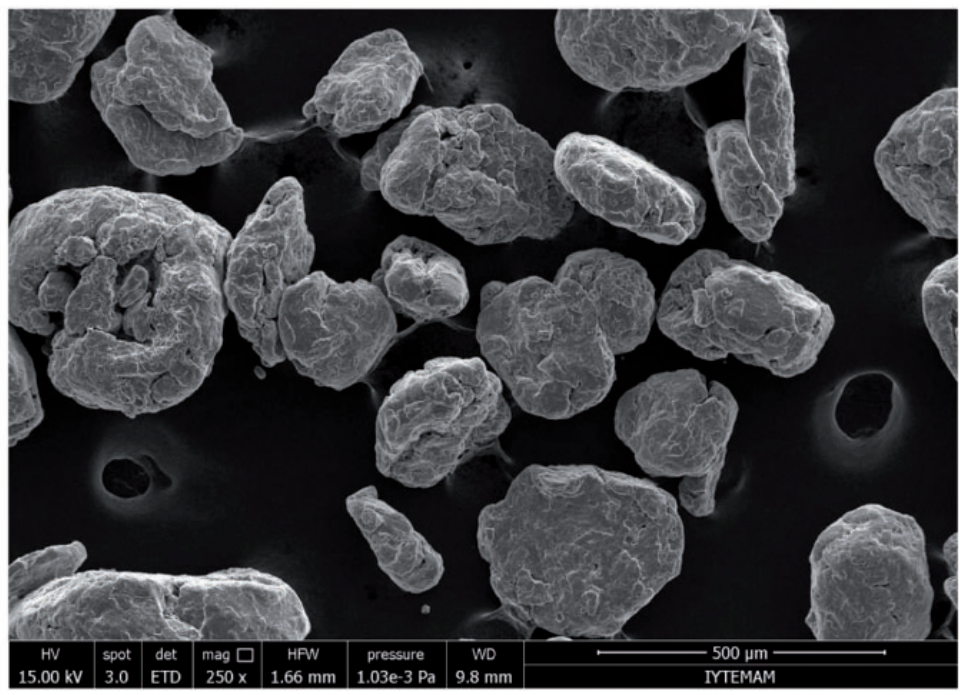

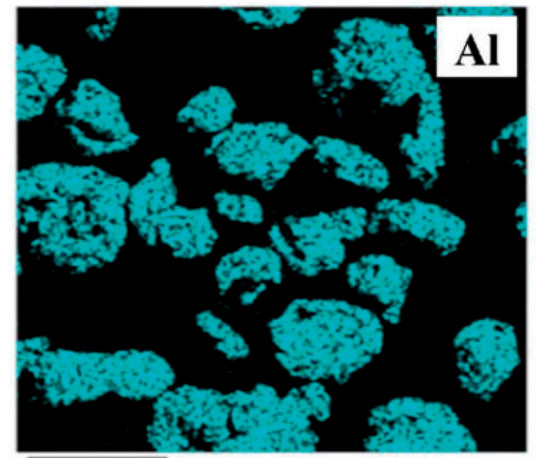

$500 \mu \mathrm{m}$

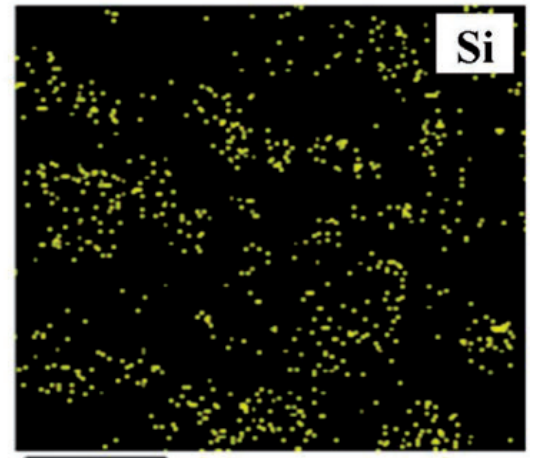

$500 \mu \mathrm{m}$

Figure 4. SE image and EDX mapping of aluminium powders and $\mathrm{SiC}$ nanoparticles after $2 \mathrm{~h}$ ball milling.

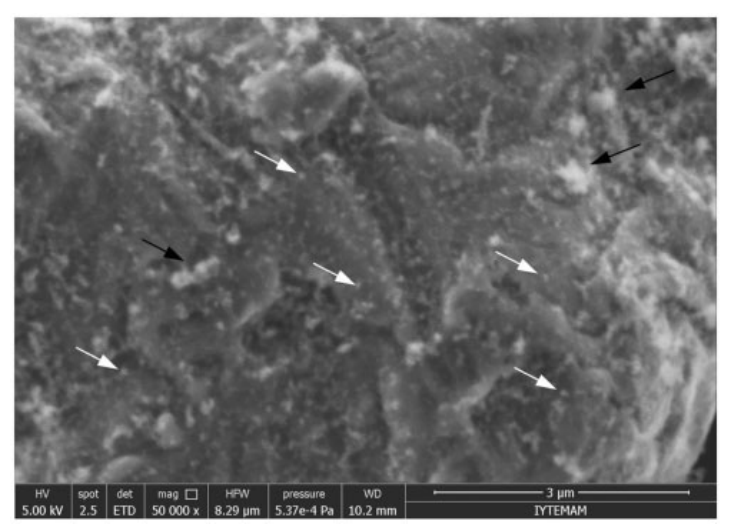

Figure 5. High-magnification SE image from a ball-milled particle indicating the dispersion of $\mathrm{SiC}$ nanoparticles on the $\mathrm{Al}$ powder (some sub-micron-sized nanoparticle clusters and individual nanoparticles are marked with black and white arrows, respectively).

the cast displayed the presence of nanoparticle/nanosized particle clusters. This may imply that a relatively uniform distribution of $\mathrm{SiC}$ nanoparticles throughout the molten A357 alloy could be obtained with a combination of the closed end tube nanoparticle feeding and ultrasonic processing.

Figure 9(a) shows a TEM image of a $\mathrm{SiC}$ nanoparticle cluster concentrated region in the fabricated nanocomposites. In this region, the SAED pattern was indexed to ensure that the particles are the original $\beta$-SiC nanoparticles fed and embedded into the matrix, not other nano-sized particles that may have been introduced or precipitated, as represented in Figure 9(b). This indexed SAED pattern indicates typical rings for single crystalline $\mathrm{SiC}$ nanoparticles with a face-centred cubic structure. Also, a high-magnification TEM image of an individual $\mathrm{SiC}$ nanoparticle is given in Figure 9(c), which does not show any distinct interlayer between the particle and $\mathrm{Al}$ matrix. Therefore, it could be suggested that no chemical reaction occurred at the interface, which is crucial for an effective bonding.

\section{Mechanical properties of the fabricated nanocomposites}

The macrohardness of ultrasonically treated A357 alloy was increased from $60 \mathrm{HV}$ to $73 \mathrm{HV}$ with the addition 


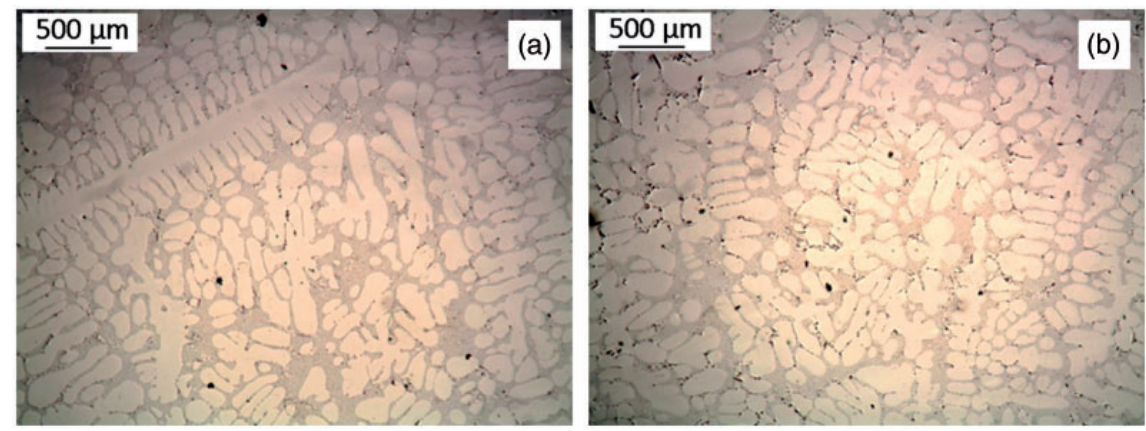

Figure 6. Optical images of the ultrasonically treated and cast A357 alloy without nanoparticles (a), and the fabricated A357/0.5 wt.\% SiC nanocomposite (b).
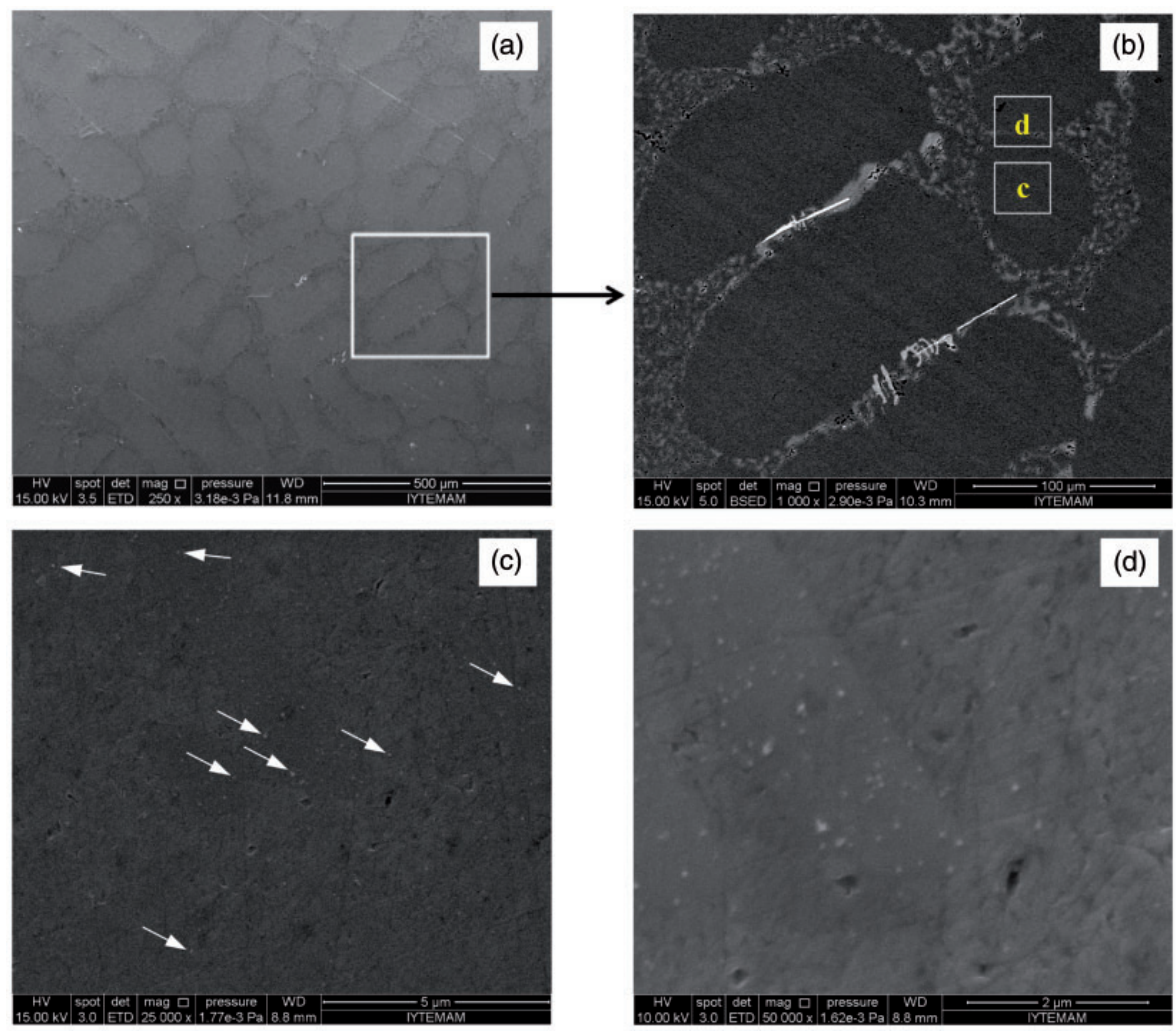

Figure 7. SEM images of the A357/0.5 wt.\% SiC nanocomposite: SE image (a), backscattered electron (BSE) image of the area shown with a white square in a (b), SE images of the areas shown in (b): inside the Al grain (c) and in the eutectic (d).

of $0.5 \mathrm{wt} . \% \mathrm{SiC}$ nanoparticles. The enhancement in the hardness is likely to be mainly due to the dislocation movement restriction effect of nanoparticles, i.e. Orowan strengthening.

Table 2 compares the tensile properties of the ultrasonically treated A357 alloys with/without SiC nanoparticles. Also, the representative tensile testing curves of the alloy and nanocomposite are given in Figure 10. It was shown that the addition of $0.5 \mathrm{wt} . \% \mathrm{SiC}$ nanoparticles into the alloy has led to significant enhancement in the $0.2 \%$ proof stress (PS), ultimate tensile strength (UTS) and ductility. The strengthening mechanisms by nanoparticles may include load bearing, grain size reduction and Orowan strengthening. However, the contribution of load bearing is suggested to be limited due to a relatively low concentration of nanoparticles with $0.8 \mathrm{wt} \%$. Therefore, the enhancements in the PS and UTS could be ascribed to the grain refinement and Orowan strengthening by nanoparticles. ${ }^{28}$ It could be also implied that the good bonding between the $\mathrm{Al}$ matrix and $\mathrm{SiC}$ nanoparticles (Figure 9(c)) may have facilitated the stress transfer in 

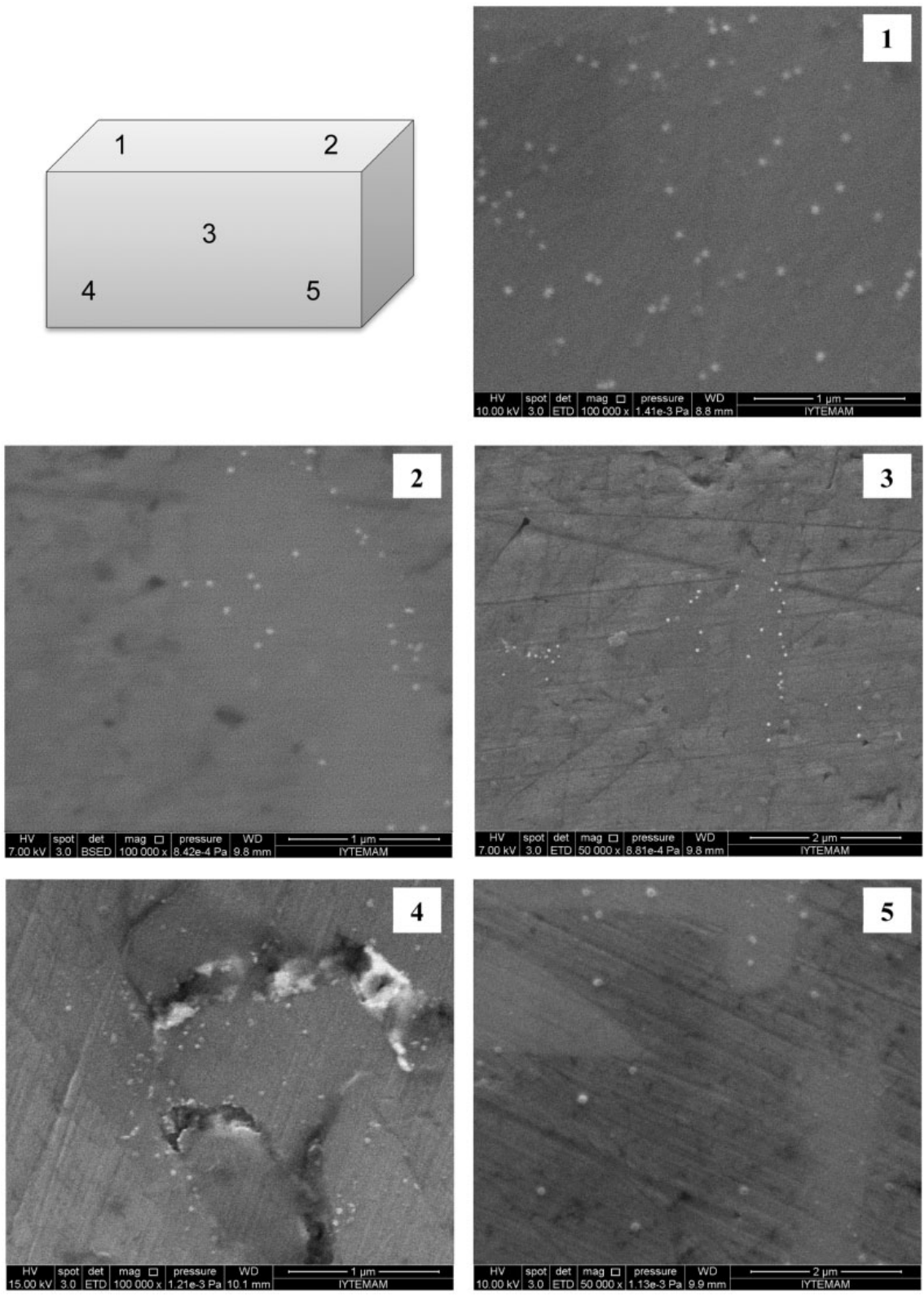

Figure 8. High-magnification SE images of $A 357 / 0.5$ wt.\% SiC nanocomposites taken from different locations of the cast block.

the nanocomposite under loading. Moreover, the notable improvement in the ductility (from 2.9 to $6.3 \%$ ) is likely to be associated with the modification of eutectic $\mathrm{Si}$ structure by the incorporation of nanoparticles. However, the other considerations such as porosity and variation in the microstructure could affect the ductility, and hence the fracture surfaces need to be investigated in detail, maybe performing in-situ high resolution SEM tensile testing to observe crack initiation and propagation.

Although there are still nano-sized $\mathrm{SiC}$ nanoparticle clusters present in the microstructure, the degree of deagglomeration of nanoparticles and particle dispersion in the whole casting has been found to be satisfactory. Nevertheless, further work is suggested to optimise the feeding mechanism, especially for larger volume castings that would be suitable for mass production.

\section{Conclusions}

In the present study, ultrasonically treated cast A357 alloys and their nanocomposites with $0.5 \mathrm{wt} . \% \mathrm{SiC}$ nanoparticles were fabricated to investigate the effect of $\mathrm{SiC}$ nanoparticles on the microstructure and mechanical properties. The closed end tube nanoparticle feeding method, in which an aluminium tube filled with the ball-milled $\mathrm{SiC}$ nanoparticles and $\mathrm{Al}$ powders 

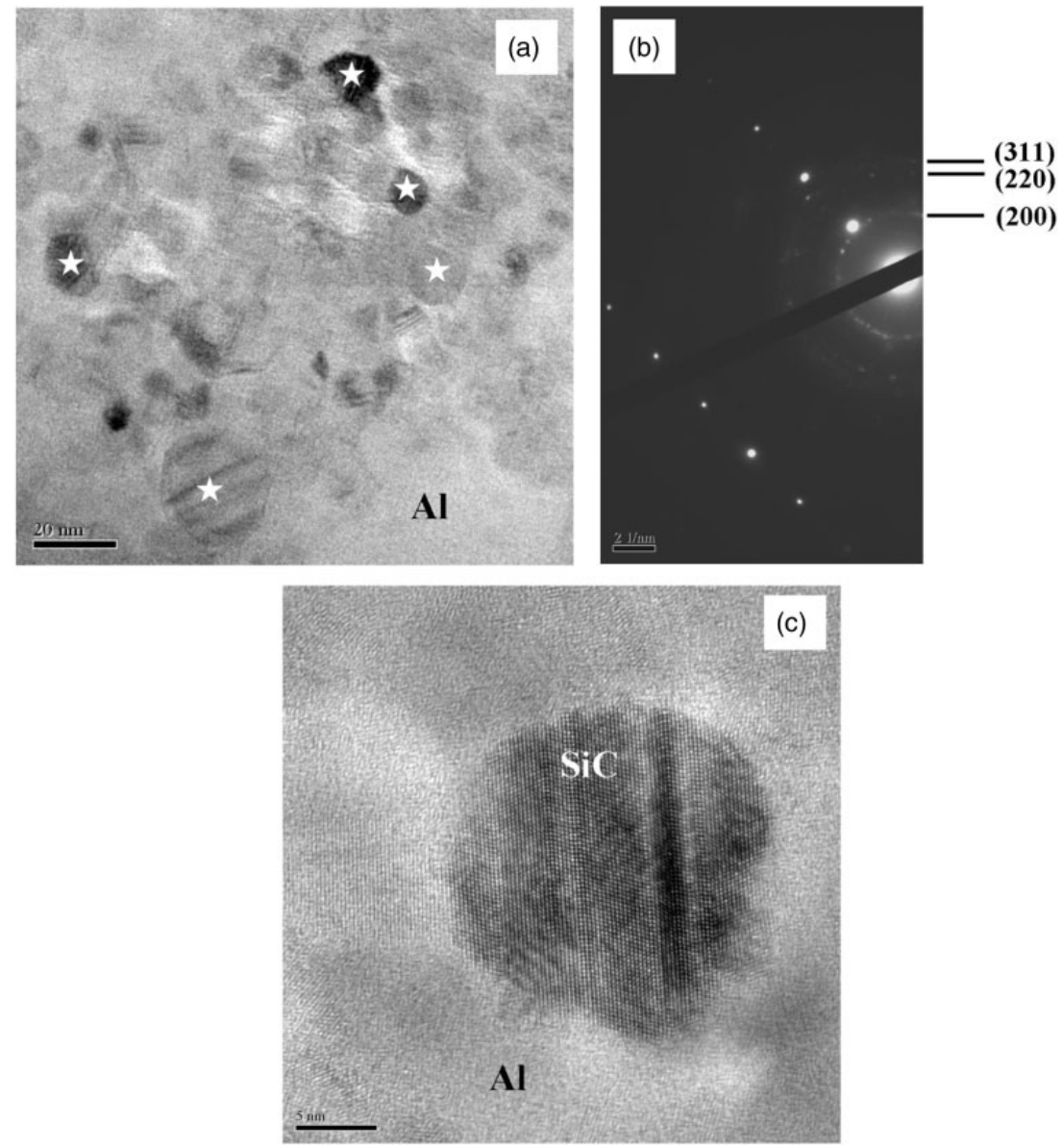

Figure 9. TEM image of the A357/0.5 wt.\% SiC nanocomposites indicating some individual SiC nanoparticles with white stars (a), indexed SAED pattern of the cluster of SiC nanoparticles in a (b), and high-magnification TEM image of an individual SiC nanoparticle embedded in the matrix (c).

Table 2. Tensile properties of ultrasonically treated A357 cast alloy and A357/0.5 wt.\% SiC cast nanocomposite.

\begin{tabular}{lcll}
\hline & $\begin{array}{l}\text { 0.2\% Proof } \\
\text { stress } \\
(\mathrm{MPa})\end{array}$ & $\begin{array}{l}\text { Ultimate } \\
\text { tensile } \\
\text { strength } \\
(\mathrm{MPa})\end{array}$ & $\begin{array}{l}\text { Elongation } \\
\text { to fracture } \\
(\%)\end{array}$ \\
Specimen & $91 \pm 4.5$ & $138 \pm 4.2$ & $2.9 \pm 0.4$ \\
\hline $\begin{array}{l}\text { Ultrasonically treated } \\
\text { A357 alloy }\end{array}$ & $\mathrm{I} 12 \pm 5.7$ & $198 \pm 10.2$ & $6.3 \pm \mathrm{I} . \mathrm{I}$ \\
$\begin{array}{l}\text { A357/0.5 wt.\% } \\
\mathrm{SiC} \text { nanocomposite }\end{array}$ & & & \\
\hline
\end{tabular}

is fed into the melt under ultrasonic cavitation, was found to be promising in terms of deagglomeration and relatively uniform dispersion of nanoparticles in the matrix. It is suggested that the relatively effective deagglomeration of nanoparticles is mainly due to the ball milling prior to the particle feeding into the melt, while their relatively uniform dispersion is most likely to be due to the application of ultrasonic cavitation.

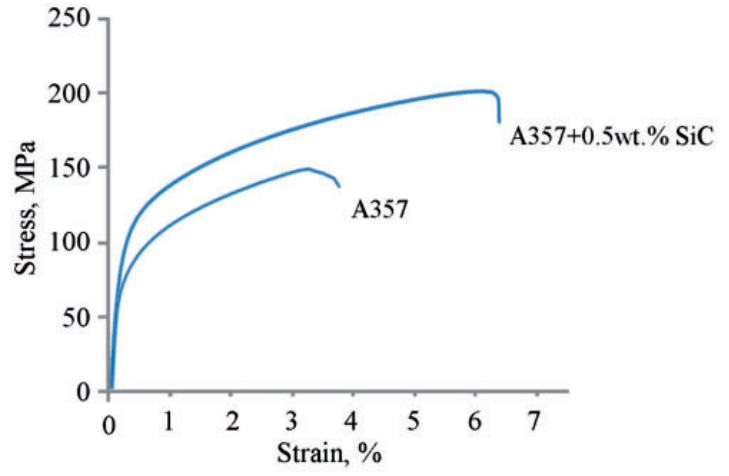

Figure 10. Representative tensile stress-strain curves of A357 alloy and $\mathrm{A} 357 / \mathrm{SiC}$ nanocomposite.

It has been shown that the introduction of $0.5 \mathrm{wt} . \%$ $\mathrm{SiC}$ simultaneously improved the hardness, $0.2 \% \mathrm{PS}$, UTS and ductility of the matrix alloy due to strengthening potency of nanoparticles. Also, the good bonding achieved between the nanoparticles and matrix is more 
likely to contribute the strength enhancement. The ball milling of initial powders demonstrated in this work provides a potential pathway for both academia and industry to develop high performance MMNCs with uniformly distributed nanoparticles. With the manipulation of ultrasonic processing parameters, such as increasing ultrasonic power and optimising probe geometry, further deagglomeration of nanoparticles could be obtained to maximise the strengthening effect of nanoparticles. This would allow nanocomposite materials with superior mechanical properties to be produced via relatively low cost ultrasonic casting method.

\section{Acknowledgments}

The staff in the Central Workshop and Materials Research Centre at Izmir Institute of Technology are thanked for their valuable help in preparing the test specimens and the provision of microscopy facilities.

\section{Declaration of Conflicting Interests}

The author(s) declared no potential conflicts of interest with respect to the research, authorship, and/or publication of this article.

\section{Funding}

The author(s) received no financial support for the research, authorship, and/or publication of this article.

\section{References}

1. Tong XC and Fang HS. Al-TiC composites in situprocessed by ingot metallurgy and rapid solidification technology: part II. Mechanical behavior. Metall Mater Trans A 1998; 29: 893-902.

2. Yang Y, Lan J and Li X. Study on bulk aluminum matrix nano-composite fabricated by ultrasonic dispersion of nano-sized $\mathrm{SiC}$ particles in molten aluminum alloy. Mater Sci Eng A 2004; 380: 378-383.

3. Hassan SF and Gupta M. Development of high performance magnesium nanocomposites using solidification processing route. Mater Sci Technol 2004; 20: 1383-1388.

4. Hassan SF and Gupta M. Effect of nano- $\mathrm{ZrO}_{2}$ particulates reinforcement on microstructure and mechanical behaviour of solidification processed elemental Mg. J Compos Mater 2007; 41: 2533-2543.

5. Ahamed $\mathrm{H}$ and Senthilkumar V. Role of nanosized reinforcement and milling on the synthesis of nanocrystalline aluminium alloy composites by mechanical alloying. J Alloys Compd 2010; 505: 772-782.

6. Bartolucci SF, Paras J, Rafiee MA, et al. Graphene-aluminum nanocomposites. Mater Sci Eng A 2011; 528: 7933-7937.

7. De Cicco M, Konishi H, Cao G, et al. Strong, ductile magnesium-zinc nanocomposites. Metall Mater Trans A 2009; 40: 3038-3045.

8. De Cicco MP, Turng LS, Li X, et al. Nucleation catalysis in aluminum alloy A356 using nanoscale inoculants. Metall Mater Trans A 2011; 42: 2323-2330.
9. Akio K, Atsushi O, Toshiro K, et al. Fabrication process of metal matrix composite with nano-size $\mathrm{SiC}$ particle produced by vortex method. J Jpn Inst Light Met 1999; 49: 149-154.

10. Tjong SC. Nanocrystalline materials, 2nd ed. London: Elsevier, 2014, pp.286-294.

11. Choi H, Jones M, Konishi H, et al. Effect of combined addition of $\mathrm{Cu}$ and aluminum oxide nanoparticles on mechanical properties and microstructure of Al-7Si0.3Mg Alloy. Metall Mater Trans A 2012; 43: 738-746.

12. Yang $\mathrm{Y}$ and Li X. Ultrasonic cavitation-based nanomanufacturing of bulk aluminum matrix nanocomposites. J Manuf Sci Eng 2007; 129: 252-255.

13. Cao G, Konishi H and Li X. Mechanical properties and microstructure of $\mathrm{Mg} / \mathrm{SiC}$ nanocomposites fabricated by ultrasonic cavitation based nanomanufacturing. J Manuf Sci Eng 2008; 130: 031105.1-031105.6.

14. Nie KB, Wang XJ, Wu K, et al. Processing, microstructure and mechanical properties of magnesium matrix nanocomposites fabricated by semisolid stirring assisted ultrasonic vibration. $J$ Alloys Compd 2011; 509: 8664-8669.

15. Li X, Yang Y and Cheng X. Ultrasonic-assisted fabrication of metal matrix nanocomposites. J Mater Sci 2004; 39: 3211-3212.

16. Lan J, Yang $\mathrm{Y}$ and $\mathrm{Li}$ X. Microstructure and microhardness of $\mathrm{SiC}$ nanoparticles reinforced magnesium composites fabricated by ultrasonic method. Mater Sci Eng A 2004; 386: 284-290.

17. Eskin GI and Eskin DG. Production of natural and synthesized aluminum-based composite materials with the aid of ultrasonic (cavitation) treatment of the melt. Ultrason Sonochem 2003; 10: 297-301.

18. Kandemir S, Weston PW and Atkinson HV. Production of $\mathrm{A} 356 / \mathrm{TiB}_{2}$ nanocomposite feedstock for thixoforming by an ultrasonic method. Solid State Phenom 2013; 192-193: 66-71.

19. Kandemir S. Semi-solid processing of metal matrix nanocomposites. $\mathrm{PhD}$ Thesis, University of Leicester, UK, 2013.

20. Choi H, Sun Y, Slater BP, et al. AZ91D/TiB 2 nanocomposites fabricated by solidification nanoprocessing. $A d v$ Eng Mater 2012; 14: 291-295.

21. Kandemir S, Atkinson HV, Weston DP, et al. Thixoforming of $\mathrm{A} 356 / \mathrm{SiC}$ and $\mathrm{A} 356 / \mathrm{TiB}_{2}$ nanocomposites fabricated by a combination of green compact nanoparticle incorporation and ultrasonic treatment of the melted compact. Metall Mater Trans A 2014; 45: 5782-5798.

22. Vorozhtsov SA, Eskin DG, Tamayo J, et al. The application of external fields to the manufacturing of novel dense composite master alloys and aluminum-based nanocomposites. Metall Mater Trans A 2015; 46: 2870-2875.

23. Jiang $\mathrm{J}$ and Wang Y. Microstructure and mechanical properties of the semisolid slurries and rheoformed component of nano-sized $\mathrm{SiC} / 7075$ aluminum matrix composite prepared by ultrasonic-assisted semisolid stirring. Mater Sci Eng A 2015; 639: 350-358. 
24. Jiang $\mathbf{J}$ and Wang $\mathrm{Y}$. Microstructure and mechanical properties of the rheoformed cylindrical part of 7075 aluminum matrix composite reinforced with nano-sized $\mathrm{SiC}$ particles. Mater Design 2015; 79: 32-41.

25. Lee JC, Byun JY, Park SB, et al. Prediction of Si contents to suppress the formation of $\mathrm{Al}_{4} \mathrm{C}_{3}$ in the $\mathrm{SiC}_{\mathrm{p}} / \mathrm{Al}$ composite. Acta Mater 1998; 46: 1771-1780.

26. Dahlem $\mathrm{O}$, Reisse $\mathrm{J}$ and Halloin $\mathrm{V}$. The radially vibrating horn: a scaling up possibility for sonochemical reactions. Chem Eng Sci 1999; 54: 2829-2838.
27. Li Y, Zhao YH, Ortalan V, et al. Investigation of aluminum-based nanocomposites with ultra-high strength. Mater Sci Eng A 2009; 527: 305-316.

28. Zhang $\mathrm{Z}$ and Chen DL. Contribution of Orowan strengthening effect in particulate-reinforced metal matrix nanocomposites. Mater Sci Eng A 2008; 483-484: 148-152. 